\title{
Prevalence of Cryptosporidiosis among Children with Diarrhoea Under Five years Admitted to Kosti Teaching Hospital, Kosti City, Sudan.
}

Abdelhakam Tamomh ( $\nabla$ abdelhakam738@gmail.com )

University of El Imam El Mahdi

AbdElhadi Agena

University of El Imam El Mahdi

Elham Elamin

University of El Imam El Mahdi

Mohammed Suliman

University of El Imam El Mahdi

Mohammed Elmadani

University of El Imam El Mahdi

Asmaa Omara

University of El Imam El Mahdi

Sahar Musa

University of El Imam El Mahdi

\section{Research Article}

Keywords: Prevalence, Cryptosporidiosis, diarrhoea, Children under 5 years, Kosti

Posted Date: April 5th, 2021

DOl: https://doi.org/10.21203/rs.3.rs-138494/v1

License: (9) (i) This work is licensed under a Creative Commons Attribution 4.0 International License.

Read Full License

Version of Record: A version of this preprint was published at BMC Infectious Diseases on April 14th, 2021. See the published version at https://doi.org/10.1186/s12879-021-06047-1. 


\section{Abstract}

Background: Cryptosporidiosis is a disease caused by infection with an intestinal coccidian parasite Cryptosporidium. Cryptosporidium species are the second leading cause of diarrheal disease and death in children in developing countries. Until now, no data have been available or published on its prevalence rate among children with diarrhoea in Sudan. This paper was therefore, designed to determine the prevalence rate of Cryptosporidium among diarrhoeic children under 5 years admitted to Kosti Teaching Hospital.

Methods: A hospital-based cross-sectional study including children with ages under 5 years old admitted to the paediatric section of the hospital between September 2020 and December 2020. A total of onehundred and fifty stool samples were collected. All stool samples were examined using the modified Ziehl Neelsen (ZN) staining technique, and examined microscopically for Cryptosporidium infection.

Results: A total of 150 children were examined out of which 70 presented with diarrhoea. A greater prevalence of $19 / 70(27.1 \%)$ of Cryptosporidium was observed in children with diarrhoea than children without diarrhoea $7 / 80$ (8.8\%). There was a significant relationship between the prevalence of Cryptosporidium and the presence of diarrhoea in children under 5 years in Kosti Teaching Hospital $(P<0.05)$. It was found that a higher prevalence was registered among children using pipe water for drinking.

Conclusions: The overall prevalence of parasite detected was $17.3 \%$ among children admitted to Kosti Teaching Hospital. The prevalence rate of the infection among Children with diarrhoea was $27.1 \%$. Studying the prevalence rate of cryptosporidiosis among diarrheic children may predict their health status, leading to a better diagnosis, treatment, and therefore, patients' status improvement.

\section{Background}

Cryptosporidium species are single-celled coccidian parasites that cause the diarrheal disease cryptosporidiosis[1-4]. They can be found in soil, food, water, and on surfaces that have been contaminated with faecal matter from infected humans or animals. Cryptosporidiosis may occur via contaminated water used for irrigation or application of agricultural chemicals flood water contacting contaminated dump tank or flume water used for post-harvest washing of infected workers [5-9]

Cryptosporidiosis is a worldwide illness caused by the coccidian parasite Cryptosporidium, which infects numerous species of vertebrates, including humans. Watery diarrhoea is the most common symptom of the disease. Abdominal cramps, vomiting, nausea, dehydration, and weight loss are other symptoms associated with cryptosporidiosis. The onset of cryptosporidiosis is generally two to ten days after becoming infected with the parasite. Symptoms are usually self-limiting in healthy individuals. Diarrhoea and dehydration may be more severe and possibly life-threatening among individuals with weakened immune systems[10-13]. 
Cryptosporidiosis is usually diagnosed with microscopic detection of the parasite oocysts, oocyst antigens, or oocyst DNA in stool samples. For the detection of oocysts in stool, the sample must be concentrated using the formalin-ether sedimentation method prior to microscopic examination. The oocysts of Cryptosporidium in unconcentrated faecal smears can be easily observed by acid-fast or phenol-auramine staining methods $[1,2,9,14-18]$.

About $30-50 \%$ of deaths in infants and children individuals resulting from cryptosporidiosis worldwide and it is the second after rotavirus leading cause of diarrhoea and deaths among children $[1,9]$.

In developing countries or low-and-middle-income countries, the parasite was gradually associated with malnutrition and death caused by diarrhoea in children [5,6,19-23]. Cryptosporidiosis, caused by the Cryptosporidium parvum, is of great concern because of associated with economic losses and the public health significance in humans. Over two-hundred water-borne, food-borne, and zoonotic cryptosporidiosis outbreaks have been registered. Cryptosporidium spp. in economically low resource countries are the second cause of diarrheal illness and death in children and remains the only member of the major diarrheal diseases for which no consistently effective therapy is available $[7,10,11,24-30]$.

Sudan is one of these countries, situated in Northeast Africa at the Nile Valley. Most epidemiological studies or surveys have reported and indicated that the infections caused by soil-transmitted helminths, Schistosoma spp., food- and water-borne protozoa, and Plasmodium spp., are endemic in Sudan [12$14,17]$. However, limited and less information is available on the prevalence rate of cryptosporidiosis among children in Sudan, and especially among children with diarrhoea. The aim of this study is to study the prevalence of Cryptosporidiosis among children with diarrhoea attending to Kosti Teaching Hospital, White Nile State, Sudan.

\section{Materials And Methods}

\section{Study area}

The research was conducted at the paediatric section and clinical laboratory department of Kosti Teaching Hospital, Kosti, Sudan. This Hospital is serving customers from Kosti city and its surrounding cities in the State. Kosti city is one of the major cities in Sudan that lies south of Khartoum, the capital of Sudan, and stands on the western bank of the White Nile river opposite Rabak (the capital of the White Nile state) where there is a bridge. However, the locality is composed of five administrative units. It is bordered by Eldewiem locality in the north, Rabak locality in the east, Al salam locality in the south, and Tendalty locality in the west. The most important water resource rainwater and while Nile. Most activities are grazing, agriculture, trade, and fishing.

\section{Study design}

This study was a hospital-based cross-sectional study conducted at Kosti Teaching Hospital Laboratory between the first of September and 30th of December, 2020. All Participants consulted or hospitalized in 
the paediatric section were included. A consecutive sampling method was performed, from which those who met our inclusion criteria and agreed to our research were directly included and selected.

\section{Study population}

The main population of this study were Children under or equal the age 5 years admitting Kosti Teaching Hospital.

\section{Inclusion criteria}

The study was restricted to children under or equal the age 5 years that have diarrhoea and without diarrhoea whose parents/guardians agreed for their children after obvious explanation for the objectives of our study in English and Arabic.

\section{Exclusion criteria}

Children above 5 years were excluded and some of those children under or equal 5 years whose parents/guardians did not agree to our study. Additionally, we excluded children whose parents could not give a clear age for them.

\section{Ethical considerations}

The study was approved by the Institutional Ethics Committee of Faculty of Medical Laboratory Sciences, University of El Imam El Mahdi.

\section{Data collection}

Questionnaires were performed to gather demographic data that included; name, age, sex, clinical symptoms including diarrhoea, patient's residence, presence of toilet facility, sources of drinking water. This questionnaire was appropriated or adapted from the research by Tombang $\mathrm{A} N$ et al in Cameron [1].

\section{Stool sample collection}

Parents/guardians of children with gastrointestinal symptoms (with diarrhoea or without diarrhoea) were given stool containers labelled to collect one stool sample on the time of collection. They were explained how to collect suitable amount of stool in the stool containers and send them to the laboratory as soon as possible.

\section{Stool sample handling and storage}

Suitable gloves were performed to take or handle the containers. The samples were checked for the stool quantity and also the physical examination was recorded. The labels of the containers were also checked and matched to the corresponded questionnaires. A fresh stool samples were kept and preserved at - 20 ${ }^{\circ} \mathrm{C}$ in the fridge in the clinical laboratory for investigations at the end of each working day. 
Modified Ziehl Neelsen (mZN) staining technique:

The stool samples were took from the laboratory fridge and putted at room temperature before faecal smears were prepared on microscope slides using a wooden stick applicators. Then the smears were left on racks to air dry.

\section{Method}

The slides were put in staining racks for fixation in absolute methanol for three minutes followed by a strong carbol fuchsin stain for 15 minutes. Then the slide was rinsed in tap water. A decolorization made by add $1 \%$ hydrochloric acid alcohol for 15 seconds, and rinsing in tap water. Then a counterstain $1 \%$ methylene blue added for 30 seconds,

rinse well, and left to air dry. The stained slides were investigated and examined using 40x and 100x objectives and the presence or absence of Oocysts was registered..

\section{Results}

Oocysts are round to ovoid in shape, and the size usually $~ 4-6 \mu \mathrm{m}$ in diameter. They are acid-fast staining. The sporulated structures or forms can be appeared as red crescentic bodies, and the sporozoites in the Oocysts, can be seen in unstained wall. The quantity of oocysts was determined as $1+$ (1-10oocysts/preparation); $2+$ (11-50oocysts/preparation); and $3+$ (>50oocysts/preparation).

\section{Statistical analysis:}

Data will be recorded and then analyzed using the Chi-square test by a statistical package of social science (SPSS version 21) program. P values $<0.05$ will be considered significant for all statistical analysis.

\section{Results}

\section{Socio-demographic characteristics of participants}

A total of 150 children with the ages under or equal 5 years old were enrolled in this study. The mean age of the children was $46.8(S D=17.7)$ years and the median age was 60 months. More than half 85 $(56.7 \%)$ of the children were male. Also, as concerns a total of $137(91.3 \%)$ or $13(8.7 \%)$, have latrines or without latrines in their homes respectively (Table 1).

The diarrhoea and stool consistency from children within the ages under or equal 5 years in Kosti $(n=$ 150)

A total of 70/150 (46.7\%) participants were presented with diarrhoea (watery/mucoid stool, and the remaining $80 / 150$ (53.3\%) children were presented with formed/semi-formed stool 
Prevalence of Cryptosporidium within age groups and the presence/absence of diarrhoea

Table 2 shows the age group less than 30 months that recorded a 10/63 (15.8\%) prevalence with respect to a $16 / 87(18.4 \%)$ for the age group equal 60 months. The participants that presented with diarrhoea recorded a $19 / 70(27.1 \%)$ prevalence while those that did not present with diarrhoea recorded a $7 / 80$ (8.8\%) prevalence (Table 2 )

Prevalence of Cryptosporidium among children under or equal the ages 5 years in Kosti that presented with diarrhoea

The overall prevalence of $26 / 150$ (17.3\%) for Cryptosporidium among children admitted to Kosti Teaching Hospital. High prevalence of Cryptosporidium (19/70, 27.1\%) was observed among children have diarrhoea than children without diarrhoea $(7 / 80,8.8 \%)$. There was a high relationship $(p=0.003)$ between prevalence of Cryptosporidium and the presence of diarrhoea among children of ages under or equal 5 years in the Kosti Teaching Hospital (Table 3).

Table 1. Demographics data of the studied patients:

\begin{tabular}{|lll|}
\hline Characteristics & Frequency $(\mathbf{n = 1 5 0})$ & Percentage \% \\
\hline Age & 63 & 42 \\
\hline$<5 y$ rs & 87 & 58 \\
\hline$=5 y$ rs & 85 & 56.7 \\
\hline Gender & 65 & 43.3 \\
\hline Male & 137 & \\
\hline Female & 13 & 91.3 \\
\hline Availability of Latrine & 8.7 \\
\hline Yes & & \\
\hline No & 116 & 77.3 \\
\hline Source of drinking water & 1 & 0.7 \\
\hline Pipe & 15 & 10 \\
\hline Canal & 18 & 12 \\
\hline Donkey cart & & \\
\hline Others & & \\
\hline
\end{tabular}

Table 2. Prevalence of Cryptosporidiosis among children according to Age and presence of diarrhoea: 


\begin{tabular}{|lllll|}
\hline Variable & Frequency & $\begin{array}{l}\text { Number of } \\
\text { Positive }\end{array}$ & $\begin{array}{l}\text { No. of Microscopy positive } \\
\text { samples by (\%) }\end{array}$ & $\begin{array}{l}\text { No. of Microscopy positive } \\
\text { samples within (\%) }\end{array}$ \\
\hline Age & 63 & 10 & 6.7 & 15.9 \\
\hline $\begin{array}{l}<30 \\
\text { months }\end{array}$ & 63 & 16 & 10.7 & 18.4 \\
\hline $\begin{array}{l}=60 \\
\text { months }\end{array}$ & 87 & 19 & 12.7 & 27.1 \\
\hline Diarrhoea & 70 & 7 & 4.7 & 8.8 \\
\hline yes & 80 & 7 & & \\
\hline No & 80 & & & \\
\hline
\end{tabular}

Table 3. Relationship of Cryptosporidium among children under 5 years in Kosti with demographics and family data: 


\begin{tabular}{|c|c|c|c|c|}
\hline Variable & $\begin{array}{l}\text { No. of stool samples } \\
\text { for each categories }\end{array}$ & $\begin{array}{l}\text { No.( } 100 \%) \text { positive } \\
\text { samples based on } \\
\text { categories }\end{array}$ & $\begin{array}{l}\text { Prevalence (17.3\%) } \\
\text { for each categories }\end{array}$ & $\begin{array}{l}P \text { - } \\
\text { value }\end{array}$ \\
\hline \multicolumn{5}{|l|}{ Age } \\
\hline$<5 y r s$ & $63(42)$ & $10(38.5)$ & $10(6.7)$ & 0.688 \\
\hline$=5 y r s$ & $87(58)$ & $16(61.5)$ & $16(10.6)$ & \\
\hline \multicolumn{5}{|l|}{ Gender } \\
\hline Male & $85(56.7)$ & 18(69.2) & $18(12)$ & 0.155 \\
\hline Female & $65(43.3)$ & $8(30.8)$ & $8(5)$ & \\
\hline \multicolumn{5}{|l|}{$\begin{array}{l}\text { Availability } \\
\text { of Latrine }\end{array}$} \\
\hline Yes & $137(91.3)$ & $23(88.5)$ & $23(15.3)$ & 0.567 \\
\hline No & $13(8.7)$ & $3(11.5)$ & $3(2)$ & \\
\hline \multicolumn{5}{|l|}{$\begin{array}{l}\text { Source of } \\
\text { drinking } \\
\text { water }\end{array}$} \\
\hline Pipe & $116(77.3)$ & 18(69.3) & $18(12)$ & 0.367 \\
\hline Canal & $1(0.7)$ & 00 & 00 & \\
\hline Donkey cart & $15(10)$ & $5(19.2)$ & $5(3.3)$ & \\
\hline Others & 18(12) & $3(11.5)$ & $3(2)$ & \\
\hline \multicolumn{5}{|l|}{ Diarrhoea } \\
\hline Yes & $70(46.7)$ & 19(73) & $19(12.7)$ & 0.003 \\
\hline No & $80(53.3)$ & $7(27)$ & $7(4.6)$ & \\
\hline
\end{tabular}

\section{Discussion}

Cryptosporidium is among the four major pathogens causing diarrheal diseases in low-and-middleincome countries, especially in children. This parasite is recognized as a highly infectious enteric pathogen and is transmitted mainly by the faecal-oral route $[1,2]$. This current study aimed to determine the prevalence rate of Cryptosporidiosis among children with diarrhoea patients admitted to Kosti Teaching hospital, Kosti city, White Nile state in Sudan. One-hundred and fifty diarrhoeic stool samples were examined using firstly direct wet preparation and formal ether concentration technique, and secondly examined using modified ZN staining technique. 
In our present findings the overall prevalence rate of cryptosporidiosis was 26 (17.3\%) among children with diarrhoea admitted to the paediatrics emergency section at Kosti Teaching Hospital using modified ziehl neelsen technique. This result is more than the result obtained in Tanzania ,Cameroon and Rwanda and benin $[1,2,3,6]$ with $10.4,8.93,9.4 \%$, and $5.8 \%$ respectively. High prevalence rate has also, been found in low-and-middle-income countries with high average rainfall such as Nigeria [5], 38.3\%. Our result is in the line with the result obtained in residents in rural areas in White Nile state in Sudan, $13.3 \%$ and near to that result obtained in Iraq[4,7 ], 21.92\%. This prevalence rate is probably justified by fact that Kosti is a city with improved access to drinkable water, latrine use, less faecal contamination rates, thus limiting the occurrence of parasitosis in general and cryptosporidiosis in particular. Also, this low prevalence may be explained by methodology, using microscopy which can be less sensitive than PCR.

Our relevance analysis explained the prevalence of cryptosporidiosis among diarrhoeic children was higher increase in males $18(12 \%)$ than female $8(5 \%)$. but there was no significant difference $(p>0.05)$. The reason for these difference is not clear since they have the same exposure at crawling stage but may be probably due to the fact that the female has less activity and being at home most of the time. This result is in the line with results obtained in Iraq[4].

In the current findings a high detection or recovery of cryptosporidium parasite was detected among the age group of five years $16(10,7 \%)$ than the age under five years old $10(6,7 \%)$. This finding is in agreement with a research carried out in Germany, and Cameron $[8,1]$ and by Centers for Disease Control $(C D C)$ in 2020 [9] where a greater prevalence rate was gained among children of the ages of 5 years than those under 5 years. In this age, the high prevalence is maybe related to the fact that this age group are usually more in danger of diarrhoea for this reason, those basal hygiene activities are unknown or not respected and pair with the truth that the immune system of the body is not well sophisticated [9]. This great prevalence rate of children with the ages equal to 5 years, because schooling ages in Sudan is usually around five years old. Also, in this age group this prevalence can be imputed to the truth that the crest of parasitism occurs at the ages of kindergarten and the ages of primary schools when community games and touch with contaminated and dirty soil. This perhaps for the reason this current research was conducted in Kosti an urban and civilian area with a multiracial population, where children find better care fed than children in rural areas where the rates of malnutrition may be greater.

Further investigations expressed the prevalence was high among children who consumed pipeline water $18(12 \%)$ than the other sources of water. Despite pipeline water with a purification system which is the main source of water for most populations in Kosti city, this high prevalence rate may be related sometime to the stopping of water purification system and it may be associated with economic improvement. The risk of using contaminated bare hands for feeding children may enable the transmission of foodborne diseases like Cryptosporidiosis from infected adults to children. These practices can generate big chances for the ingestion of contaminated food and water with oocysts shed from infected individuals with Cryptosporidium. This elaborates why Cryptosporidium is ranked 5th among the most important foodborne parasites globally $[2,5,7,30]$. 


\section{Conclusion}

The overall prevalence of Cryptosporidiosis among children under or equal 5 years that admitted to Kosti Teaching Hospital was $17.3 \%$. The Prevalence rate among children that have diarrhoea was $27.1 \%$. Children whose parents were using pipe water for drinking registered a higher prevalence. additionally, there is an association between Cryptosporidium and diarrhoea among children of ages under or equal 5 years admitted with diarrhoea in Kosti. Our findings clearly explained that Cryptosporidium is an essential causative agent of diarrhoea for children in Kosti. It necessary to build or improve more water purification systems and sanitation facilities to help the access of population of this area to clean drinking water for preventing cryptosporidium infection. Health education and personal hygiene programs should be held to teach the people how to avoid the infection.

\section{Limitation of the study:}

Freezing and thawing of stool samples may lead to fragmentation of oocysts and undercounting.

\section{Declarations}

\section{Ethics approval and consent to participate}

The Institutional Ethics Committee of Faculty of Medical Laboratory Sciences, University of El Imam El Mahdi approved the study. As children under or equal to the age of 5 years are involved in the study and their parents are involved in the questionnaire, and the informed consent is obtained from parents or legal guardians for themselves and for the involvement of their children. All participants were adequately informed about their rights, regulations, and all relevant guidelines or aspects of the research, including it is purpose and interview of the methods. And all methods were performed in accordance with the relevant guidelines and regulations/declaration of Helsinki.

\section{Consent for publication}

Not applicable

\section{Availability of data and materials}

The data used to support the findings of this study are available from the corresponding author upon request.

\section{Competing interests}

None declared

\section{Funding:}

None. 


\section{Authors' contributions:}

AGT, AMA, EE, MAS, ME, ABO and SAM conceived and designed the study: AGT and AMA implement the study: AGT supervised the study: EE and MAS conducted data analysis: AGT, AMA, EE, MAS, ME, ABO and SAM interpreted study results: AGT wrote the first draft of the manuscript, while AMA, EE, MAS, and ME reviewed and corrected the manuscript. All authors read and approved the final manuscript.

\section{Acknowledgements:}

Not applicable.

\section{References}

1. Tombang AN, Ambe NF, Bobga TP, et al. Prevalence and risk factors associated with cryptosporidiosis among children within the ages 0-5 years attending the Limbe regional hospital, southwest region, Cameroon. BMC public health. 2019 Dec 1;19(1):1144.

2. Razzolini MTP, Breternitz BS, Kuchkarian B, Bastos VK. Cryptosporidium and Giardia in urban wastewater: A challenge to overcome. Environ Pollut. 2020;257:113545.

3. Kabayiza JC, Andersson ME, Nilsson S, Bergström T, Muhirwa G, Lindh M. Real-time PCR identification of agents causing diarrhea in Rwandan children less than 5 years of age. Pediatr Infect Dis J. 2014; 33(10):1037-42.

4. Salman YJ, Sadek WS, Rasheed ZK. Prevalence of Cryptosporidium parvum among Iraqi displaced people in Kirkuk city using direct microscopy, flotation technique and ELISA-copro antigen test. Int. J. Curr. Microbiol. App. Sci. 2015;4(11):559-72.

5. Aniesona AT, Bamaiyi PH. Retrospective study of cryptosporidiosis among Diarrhoeic children in the arid region of north-eastern Nigeria. Zoonoses Public Health. 2014;61(6):420-6

6. Ogouyèmi-Hounto $A$, Alihonou $F$, Aholoukpe IE, et al. Prevalence of cryptosporidiosis infection among children under 5-years in Cotonou, Benin. Journal of Parasitology and Vector Biology. 2017 Jun 30;9(6):89-94.

7. Sim S, Yu JR, Lee YH, et al. Prevalence of Cryptosporidium infection among inhabitants of 2 rural areas in White Nile State, Sudan. The Korean journal of parasitology. 2015 Dec;53(6):745.

8. Chalmers RM, Cacciò S. Towards a consensus on genotyping schemes for surveillance and outbreak investigations of Cryptosporidium, Berlin, June 2016. Eurosurveillance. 2016 Sep 15;21(37):30338.

9. www.cdc.gov/parasite; Last updated 5, 2019, Accessed 13,11,2020.

10. Khalil IA, Troeger C, Rao PC, et al. Morbidity, mortality, and long-term consequences associated with diarrhoea from Cryptosporidium infection in children younger than 5 years: a meta-analyses study. The Lancet Global Health. 2018 Jul 1;6(7):e758-68. 
11. Tamomh AG, Suliman MA, Cedric KK, et al. The role of two parasitological staining techniques in diagnosis of cryptosporidiosis among diarrheic patient's admitted to Kosti teaching hospital. White Nile state, Sudan. MOJ Public Health. 2018;7(2):54-7.

12. Tamomh AG, Yousfi SR, Abakar AD, Nour BY. Prevalence of Intestinal Schistosomiasis among Basic School Children in White Nile Sugar Scheme a New Irrigated Project, White Nile State, Sudan. Biol Med (Aligarh). 2018;10(425):2.

13. Tamomh AG, Elamin E, Suliman MA, et al. Intestinal parasitic infections among hemodialysis Sudanese patients. Microbes and Infectious Diseases. 2020 Oct 26.

14. Tamomh AG, Abakr AD, Nour BY. Urinary Schistosomiasis among basic school children in a new irrigated sugar scheme area, White Nile State, Sudan. J Microbiol Exp. 2018;6(2):93-6.

15. Majeed QA, El-Azazy OM, Abdou NE, et al. Epidemiological observations on cryptosporidiosis and molecular characterization of Cryptosporidium spp. in sheep and goats in Kuwait. Parasitology research. 2018 May 1;117(5):1631-6.

16. Tamomh AG, Yousif SR, Weldegiorgis TZ, et al. Prevalence of cryptosporidiosis among diarrhoeic patient's attending to kosti teaching hospital, White Nile State, Sudan. Wjpmr. 2018,4(2), 25-30.

17. Wang ZD, Liu Q, Liu HH, et al. Prevalence of Cryptosporidium, microsporidia and Isospora infection in HIV-infected people: a global systematic review and meta-analysis. Parasites \& vectors. 2018 Dec 1;11(1):28.

18. Florescu DF, Sandkovsky U. Cryptosporidium infection in solid organ transplantation. World journal of transplantation. 2016 Sep 24;6(3):460.

19. Sannella AR, Suputtamongkol Y, Wongsawat E, Cacciò SM. A retrospective molecular study of Cryptosporidium species and genotypes in HIV-infected patients from Thailand. Parasites \& vectors. 2019 Dec;12(1):1-6.

20. Arora, D. R and Arora, B. B. Medical parasitology, 3rd edition. New Delhi. CBS publishers and distributers pVT. LTD.2010. pages

21. Cheesbrough, M. Medical laboratory manual for tropical contries. 2 nd edition. British university.1999. pages

22. Zahedi A, Paparini A, Jian F, Robertson I, Ryan U. Public health significance of zoonotic Cryptosporidium species in wildlife: critical insights into better drinking water management. International Journal for Parasitology: Parasites and Wildlife. 2016 Apr 1;5(1):88-109.

23. Ehsan MA, Akter M, Ahammed M, Ali MA, Ahmed MU. Prevalence and clinical importance of Cryptosporidium and Giardia in human and animals. Bangladesh Journal of Veterinary Medicine. 2016;14(2):109-22.

24. Squire SA, Ryan U. Cryptosporidium and Giardia in Africa: current and future challenges. Parasites \& vectors. 2017 Dec 1;10(1):195.

25. Saeed AS, Abd Alla AB, Abdullah HS, et al. Prevalence of Cryptosporidiosis and Intestinal Parasites among Immunocompromised Patients in Khartoum State-Sudan. Global Advanced Research Journal of Microbiology. 2018; 7(5).098-103 
26. Wang RJ, Li JQ, Chen YC, Zhang LX, Xiao LH. Widespread occurrence of Cryptosporidium infections in patients with HIV/AIDS: Epidemiology, clinical feature, diagnosis, and therapy. Acta tropica. 2018 Nov 1;187:257-63.

27. Gunasekera S, Zahedi A, O'Dea M, et al. Organoids and bioengineered intestinal models: Potential solutions to the Cryptosporidium culturing dilemma. Microorganisms. 2020 May;8(5):715.

28. Yimer M, Hailu T, Mulu W, Abera B. Evaluation performance of diagnostic methods of intestinal parasitosis in school age children in Ethiopia. BMC research notes. 2015 Dec;8(1):1-5.

29. Mengist HM, Demeke G, Zewdie O, Belew A. Diagnostic performance of direct wet mount microscopy in detecting intestinal helminths among pregnant women attending ante-natal care (ANC) in East Wollega, Oromia, Ethiopia. BMC research notes. 2018 Dec 1;11(1):276.

30. Zheng H, He J, Wang L, Zhang R, Ding Z, Hu W. Risk factors and spatial clusters of Cryptosporidium infection among school-age children in a rural region of eastern China. International journal of environmental research and public health. 2018 May;15(5):924. 